\title{
One-step ionic liquid-based ultrasound-assisted dispersive liquid-liquid microextraction coupled with high-performance liquid chromatography for the determination of pyrethroids in traditional Chinese medicine oral liquid preparations
}

\author{
Yiyi Liao', Yuge Hou', Yan Zhong ${ }^{1}$, Hong Chen' ${ }^{1}$ Chang Xu' ${ }^{1}$, Makoto Tsunoda², Yingxia Zhang ${ }^{1}$, Shiming Deng \\ and Yanting Song ${ }^{1 *}$ (D)
}

\begin{abstract}
In this study, a simple one-step ionic liquid-based ultrasound-assisted dispersive liquid-liquid microextraction technique was coupled with high-performance liquid chromatography for the analysis of four pyrethroids in three kinds of traditional Chinese medicine oral liquid preparations: simotang oral liquid, kangbingdu oral liquid, and huaji oral liquid. The extraction parameters were examined to improve extraction efficiency. The optimum extraction conditions were $50 \mu \mathrm{L}$ of 1-octyl-3-methylimidazolium hexafluorophosphate utilized as the extraction solvent and $800 \mu \mathrm{L}$ of acetonitrile applied as the dispersive solvent. The extraction was assisted by ultrasonication for $8 \mathrm{~min}$. The limits of detection for the four pyrethroids were within $0.007-0.024 \mathrm{mg} \mathrm{L}^{-1}$, and the limits of quantitation ranged between 0.023 and $0.080 \mathrm{mg} \mathrm{L}^{-1}$. The accuracy of the pyrethroid determination ranged from 80.1 to $106.4 \%$. It was indicated that the proposed ionic liquid-based ultrasound-assisted dispersive liquid-liquid microextraction method had an easy operation and was accurate and environmentally friendly. This approach has potential for the analysis of pyrethroids in traditional Chinese medicine oral liquid preparations.
\end{abstract}

Keywords: Trace analysis, Dispersive solvent, Traditional Chinese medicine, Pyrethroids, Ultrasound

\section{Introduction}

Traditional Chinese medicine (TCM) is widely employed in the treatment of a variety of diseases, including cough, hyperlipidemia, hypertension and infectious diseases $[1$, 2]. During the cultivation of Chinese herbal medicine, pesticides are commonly used to control pests and diseases. Currently, synthetic pyrethroid insecticides are

\footnotetext{
*Correspondence: songyt@hainanu.edu.cn

${ }^{1}$ Key Laboratory of Tropical Biological Resources of Ministry

of Education; Department of Pharmaceutical Sciences, School of Life and Pharmaceutical Sciences, Hainan University, Haikou 570228, China

Full list of author information is available at the end of the article
}

more frequently used than traditional organophosphate [3], organonitrogen [4], organochlorine [5], and carbamate pesticides [6] because of their strong insecticidal activity and good stability upon exposure to light and air [7]. However, numerous studies have indicated that these pyrethroid pesticides are toxic to the nervous, reproductive, immune and cardiovascular systems [8]. Oral liquid is one of the most commonly used TCM preparations, and residues of pyrethroid pesticides in TCM oral liquid preparations greatly affect the patients' health and course of therapy. Because TCM preparation contains a great many of herbal components, the interference of complex matrix to the pyrethroid residues and the limitation of 
current analytical methods will make the residue analysis of pyrethroid pesticides very difficult. Therefore, an accurate measurement method for the pyrethroid pesticides in TCM oral liquid preparations is urgently required.

Varieties of methods have been exploited for the measurement of pyrethroid residues, and the potential analytical methods include gas chromatography with electron capture detection [9] or mass spectrometry (MS) [10] and high-performance liquid chromatography (HPLC) with ultraviolet (UV) detection [11], diode array detection [12], or MS [13]. MS significantly improved the analysis of pyrethroid residues owing to its high sensitivity; however, it has stricter instrumentation requirements and is not suitable for some typical analytical laboratories. Among these techniques, HPLC-UV has been frequently employed in the analysis of pyrethroid residues [14-16]. However, the analysis of pyrethroid residues in TCM oral liquid preparations is difficult because of the extremely low pyrethroid concentrations and the complexity of the TCM sample. Therefore, pretreatment of the sample before HPLC analysis is crucial for the whole analysis process. Several approaches have been employed for the extraction of pyrethroids from samples, and these methods include the Soxhlet extraction [17], ultrasonic extraction [18], liquid-liquid extraction [19], and solid-phase extraction [20]. However, the extraction approaches have certain limitations, including large organic solvent consumption and a time-consuming extraction procedure.

Recently, ionic liquids (ILs) - semi-organic molten salts with an organic or inorganic anion and an organic cation-have emerged as alternative extraction solvents for sample treatment because of their advantages of strong thermal stability, good miscibility with organic and aqueous solvents, low vapor pressure, and good solubility for both organic and inorganic compounds. ILs have been utilized for the analysis of several kinds of organic compounds, such as benzoylurea insecticides, neonicotinoid insecticides, and endocrine-disrupting compounds [2123]. Compared with conventional extraction methods, less organic solvent was consumed during IL dispersive liquid-liquid microextraction, and a higher extraction efficiency was achieved within a shorter extraction time.

The current study was performed to exploit a one-step ionic liquid dispersive liquid-liquid microextraction (ILDLLME) for the sensitive measurement of the pyrethroid insecticide in TCM oral liquid preparations. In the current research, ultrasound technology was utilized to cause the ILs to disperse into the aqueous phase as well as to enrich the efficiency. The extraction conditions were examined to improve extraction efficiency. The current approach was then employed in the trace measurement of four pyrethroid insecticides in TCM oral liquid preparations.

\section{Methods}

\section{Reagents and materials}

Four pyrethroids (beta-cyfluthrin, bifenthrin, tau-fluvalinate and fenvalerate, Fig. 1) were purchased from Dr. Ehrenstorfer GmbH (Germany). The ILs 1-butyl3-methylimidazolium hexafluorophosphate $\left(\left[\mathrm{C}_{4} \mathrm{MIM}\right]\right.$ $\left.\left[\mathrm{PF}_{6}\right]\right)$, 1-hexyl-3-methylimidazolium hexafluorophosphate $\left(\left[\mathrm{C}_{6} \mathrm{MIM}\right]\left[\mathrm{PF}_{6}\right]\right)$, and 1-octyl-3-methylimidazolium hexafluorophosphate $\left(\left[\mathrm{C}_{8} \mathrm{MIM}\right]\left[\mathrm{PF}_{6}\right]\right)$ were provided by the Lanzhou Institute of Chemical Physics, Chinese Academy of Sciences (Gansu, China). Acetonitrile (HPLC grade) was supplied by Mreda Corporation (USA). Water from a Milli-Q system (MA, USA) was employed after purification step. Three pyrethroid-free TCM oral liquid preparations were investigated in this study. Simotang oral liquid (composed of Aucklandia lappa Decne, Citrus aurantium L., Areca catechu L., and Lindera aggregata (Sims) Koster) was provided by Hansen Pharmaceutical Co., Ltd. (YiYang, China). Kangbingdu oral liquid (composed of Isatis indigotica Fort, Phragmites communis Trin, Curcuma zvenyujin Y. H. Chen et C. Ling, Anemarrhena asphodeloides Bge, Acortw tatarinowii Schott, Pogostemon cablin (Blanco) Benth, and Forsythia suspensa (Thunb.) Vahl) was obtained from Topsun Youbang Pharmaceutical Co., Ltd. (Huainan, China). Huaji oral liquid (composed of Poria cocos (Schw.) Wolf, Sepia esculenta Hoyle, Callus gallus domesticus Brisson, Sparganium stoloniferum Buch-Ham, Curcuma phaeocaulis Val, Carthamus tinctorius L., Areca catechu L., Omphalia lapidescens Schroet, Carpesium abrotanoides L., and Quisqualis indica L.) was provided by Chengzhi Pharmaceutical Co., Ltd. (Yongfeng, China).

\section{Apparatus}

A KQ2200DE ultrasonic generator provided by Kunshan Ultrasonic Instruments Co., Ltd. (Jiangsu, China) was operated with an output power and frequency of $100 \mathrm{~W}$ and $40 \mathrm{kHz}$, respectively. An AXTGL16M desktop highspeed refrigerated centrifuge was purchased from Anxin Technologies Inc. (Jiangsu, China).

\section{Chromatographic conditions}

The determination of pyrethroids was implemented on an HPLC system (Waters Corporation, USA) with a 1525 HPLC pump and a 2489 UV/visible detector. A Diamonsil C18 column $(5 \mu \mathrm{m}, 4.6 \mathrm{~mm}$ id $\times 150 \mathrm{~mm})$ from Dikma Technologies Inc. (Beijing, China) was used. Eluent A was water/acetonitrile $(95 / 5, \mathrm{v} / \mathrm{v})$, and eluent $\mathrm{B}$ was water/acetonitrile $(5 / 95, \mathrm{v} / \mathrm{v})$. The mobile phases were eluted according to the following program: $12 \%$ (A) from 0 to $9.0 \mathrm{~min}$, followed by $12-0 \%$ (A) from 9.0 to $35.0 \mathrm{~min}$. The flow rate was $0.6 \mathrm{~mL} \mathrm{~min}^{-1}$, and the column temperature was $30^{\circ} \mathrm{C}$. The detection was monitored at $210 \mathrm{~nm}$. 


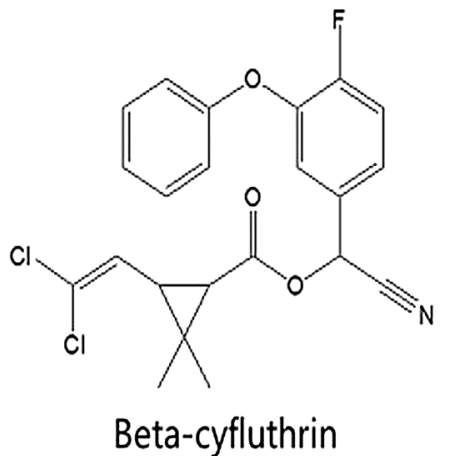<smiles>CC(C)C(C#N)(C(=O)OCc1cccc(Oc2ccccc2)c1)c1ccc(Cl)cc1</smiles>

Fenvalate<smiles>CC(C)C(Nc1ccc(C(F)(F)F)cc1Cl)C(=O)OC(C#N)c1cccc(Oc2ccccc2)c1</smiles>

Tau-fluvalinate<smiles>Cc1c(COC(=O)C2C(C=C(Cl)C(F)(F)F)C2(C)C)cccc1-c1ccccc1</smiles>

Bifenthrin

Fig. 1 Chemical structures of four pyrethroids

\section{Optimization of IL-DLLME extraction method}

The effects of extraction conditions, including the type of IL, IL volume, type of dispersive solvent, dispersive solvent amount, and ultrasonic extraction time, on the recoveries were optimized by single-factor experiments. The experiments were all carried out in triplicate.

\section{IL-DLLME procedure}

The TCM oral liquid preparations were centrifuged at $8000 \mathrm{rpm}$ for $30 \mathrm{~min}$, and the supernatant was filtered by a membrane filter $(0.22 \mu \mathrm{m})$ before the ILDLLME procedure. Then, $50 \mu \mathrm{L}$ of $\left[\mathrm{C}_{8} \mathrm{MIM}\right]\left[\mathrm{PF}_{6}\right]$ and $800 \mu \mathrm{L}$ of acetonitrile were measured by microsampler and pipette respectively, and added to $5 \mathrm{~mL}$ of the filtered sample solutions in a conical tube. The ultrasound-assisted extraction (output power of $100 \mathrm{~W}$ and frequency of $40 \mathrm{kHz}$ ) was carried out for $8 \mathrm{~min}$. Subsequently, $8 \mathrm{~mL}$ of the sample was centrifuged at $6153 \times g$ for $5 \mathrm{~min}$. The pyrethroids were extracted into a droplet of IL settled at the bottom of the tube. A syringe was used to remove the upper aqueous phase. The IL phase containing the analytes was diluted with $70 \mu \mathrm{L}$ of acetonitrile. Ultimately, $10 \mu \mathrm{L}$ of the resultant solution was delivered into the chromatographic system for analysis.

\section{Calculations}

The enrichment factor (EF), defined as the ratio of the final concentration in the sediment phase $\left(C_{\text {fin }}\right)$ to the initial target component concentration in the TCM oral liquid preparation $\left(\mathrm{C}_{\mathrm{ini}}\right)$, was calculated as:

$$
\mathrm{EF}=\frac{\mathrm{C}_{\text {fin }}}{\mathrm{C}_{\text {ini }}}
$$

The extraction recovery (ER), which was utilized to estimate the pretreatment procedure under various experimental conditions, was calculated as follows:

$$
\mathrm{ER}=\frac{\mathrm{C}_{\text {fin }} \times \mathrm{V}_{\text {fin }}}{\mathrm{C}_{\text {ini }} \times \mathrm{V}_{\text {ini }}} \times 100 \%
$$

where $V_{\text {fin }}$ is the final target component concentration in the sediment phase and $\mathrm{V}_{\text {ini }}$ is the initial target component concentration in the TCM oral liquid preparation [23]. 


\section{Preparation of spiked samples}

Spiked samples were prepared by spiking appropriate amount of the standard solutions in the TCM oral liquid preparations to yield final concentrations of 20, 50 and $100 \mu \mathrm{g} \mathrm{L}^{-1}$ for four pyrethroids, respectively. Then the samples were subsequently prepared according to the upper IL-DLLME procedure.

\section{Results and discussion}

\section{Type of IL}

The proper extraction solvent is vital for the success of the IL-DLLME process. The proper extraction solvent should have several key characteristics, including good chromatographic behavior, higher density than water, and lower water solubility [22, 24]. Three hydrophobic ILs $\left(\left[\mathrm{C}_{4} \mathrm{MIM}\right]\left[\mathrm{PF}_{6}\right],\left[\mathrm{C}_{6} \mathrm{MIM}\right]\left[\mathrm{PF}_{6}\right]\right.$ and $\left.\left[\mathrm{C}_{8} \mathrm{MIM}\right]\left[\mathrm{PF}_{6}\right]\right)$ were studied for IL-UA-DLLME in this study. However, the cloudy phase of $\left[\mathrm{C}_{4} \mathrm{MIM}\right]\left[\mathrm{PF}_{6}\right]$ was difficult to form in the IL-DLLME process; therefore, $\left[\mathrm{C}_{6} \mathrm{MIM}\right]\left[\mathrm{PF}_{6}\right]$ and $\left[\mathrm{C}_{8} \mathrm{MIM}\right]\left[\mathrm{PF}_{6}\right]$ were compared for the extraction of four pyrethroid pesticides from TCM oral liquid preparations in the subsequent experiments. As presented in Fig. 2a, $\left[\mathrm{C}_{8} \mathrm{MIM}\right]\left[\mathrm{PF}_{6}\right]$ obtained higher extraction recoveries than those of $\left[\mathrm{C}_{6} \mathrm{MIM}\right]\left[\mathrm{PF}_{6}\right]$. The longer alkyl chain may decrease the water solubility of IL, which contributes to higher extraction recoveries. Thus, $\left[\mathrm{C}_{8} \mathrm{MIM}\right]\left[\mathrm{PF}_{6}\right]$ was applied as the extraction solvent during this research.

\section{IL volume}

When a smaller amount of IL was used, a small amount of precipitation formed, which indicated that the target compound could not be extracted efficiently and that repeatability was poor. In contrast, excess IL may decrease the enrichment factor and sensitivity of the analytical method. The optimum extraction volume of $\left[\mathrm{C}_{8} \mathrm{MIM}\right]\left[\mathrm{PF}_{6}\right]$ was examined by the comparison of three different volumes $(40 \mu \mathrm{L}, 50 \mu \mathrm{L}$, and $60 \mu \mathrm{L})$. It could be observed that higher recoveries were obtained when $50 \mu \mathrm{L}$ and $60 \mu \mathrm{L}$ of $\left[\mathrm{C}_{8} \mathrm{MIM}\right]\left[\mathrm{PF}_{6}\right]$ were used (Fig. 2b). Considering the enrichment factor and sensitivity of the analytical method, a lower volume of IL was preferred, and $50 \mu \mathrm{L}$ of $\left[\mathrm{C}_{8} \mathrm{MIM}\right]\left[\mathrm{PF}_{6}\right]$ was employed during the extraction.

\section{Type of dispersive solvent}

To reduce interfacial tension and increase surface area between the two phases, a proper dispersive solvent with excellent miscibility during the one-step ionic liquid-based ultrasound-assisted dispersive liquid-liquid microextraction (IL-UA-DLLME) process is necessary.
Methanol, acetonitrile and acetone were investigated (Fig. 2c). A higher extraction efficiency was achieved when the dispersive solvent was acetonitrile. Thus, acetonitrile was applied for the dispersive solvent.

\section{Dispersive solvent amount}

The effect of the acetonitrile amount was examined by varying the amount from 700 to $900 \mu \mathrm{L}$ (Fig. 2d). The highest extraction recovery was achieved with $800 \mu \mathrm{L}$ of acetonitrile. Therefore, $800 \mu \mathrm{L}$ of acetonitrile was added during the extraction procedure.

\section{Ultrasonic extraction time}

The ultrasonic extraction time was investigated from 6 to 9 min (Fig. 2e). When the ultrasonic extraction time was changed from 6 to $8 \mathrm{~min}$, the recovery increased. However, with further extension of the extraction time from 8 to $9 \mathrm{~min}$, the extraction recovery did not greatly vary. As a consequence, 8 min was selected as the ultrasonic extraction time.

\section{Analysis of real TCM oral liquid preparations}

Pyrethroid-free TCM samples were employed as blanks for the analytical method validation. As shown in Table 1, the limits of detection (LODs, signal/noise $=3$ ) for the four pyrethroids were within $0.007-0.024 \mathrm{mg} \mathrm{L}^{-1}$, and the limits of quantitations (LOQs, signal/noise $=10$ ) were within $0.023-0.080 \mathrm{mg} \mathrm{L}^{-1}$. The linearity was investigated within $0.1-10 \mathrm{mg} \mathrm{L}^{-1}$. The peak areas versus the injection amount was plotted, and linear regression equations were obtained. The correlation coefficients of the four pyrethroids were greater than 0.999 .

As presented in Table 1, the relative standard deviation (RSD) values were $0.8-2.9 \%$ for the intra-day precision and $0.7-3.9 \%$ for the inter-day precision. The pyrethroids in spiked samples were determined at three concentrations (20, 50 and $\left.100 \mu \mathrm{g} \mathrm{L}^{-1}\right)$. As shown in Table 2, the average recoveries were within $80.1-106.4 \%$.

Three kinds of TCM oral liquid preparations (simotang, kangbingdu, and huaji) were obtained from a local community pharmacy and were analyzed with HPLCUV after the IL-UA-DLLME procedure. A typical highperformance liquid chromatogram under the conditions described in "Chromatographic conditions" section is shown in Fig. 3. The pyrethroids were separated successfully in the spiked oral liquid $\left(0,20\right.$ and $\left.100 \mu \mathrm{g} \mathrm{L}^{-1}\right)$ and spiked blank $\left(50 \mu \mathrm{g} \mathrm{L}^{-1}\right)$, indicating that the components in the TCM oral liquid preparations did not interfere with the analysis of the pyrethroids. Thus, the IL-DMLLE 

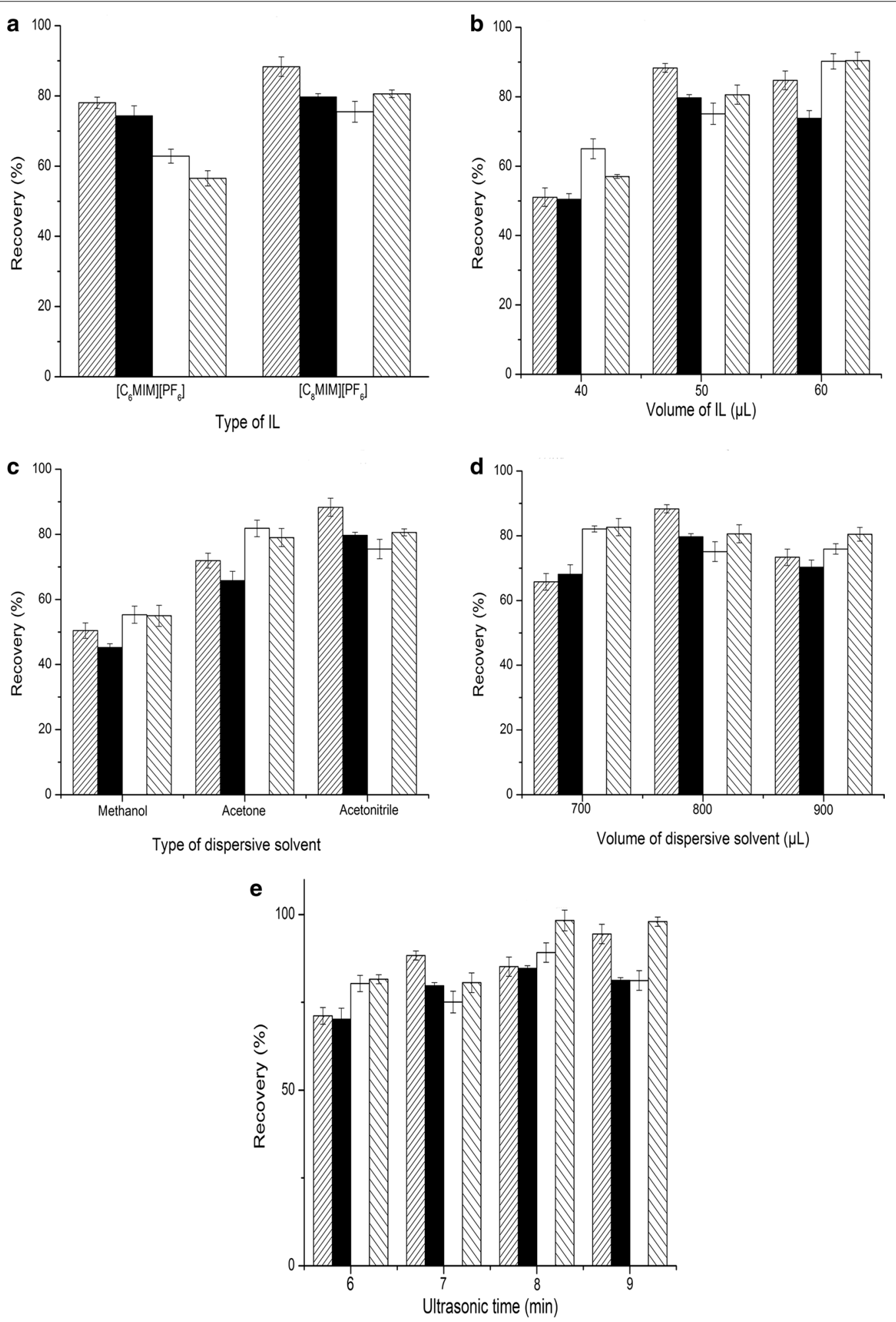

ZZA beta-cyfluthrin

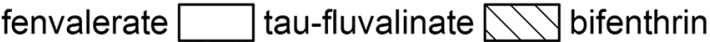

Fig. 2 Effect of IL type (a), IL volume (b), dispersive solvent type (c), dispersive solvent volume (d) and ultrasonic extraction time (e) on the extraction recovery 


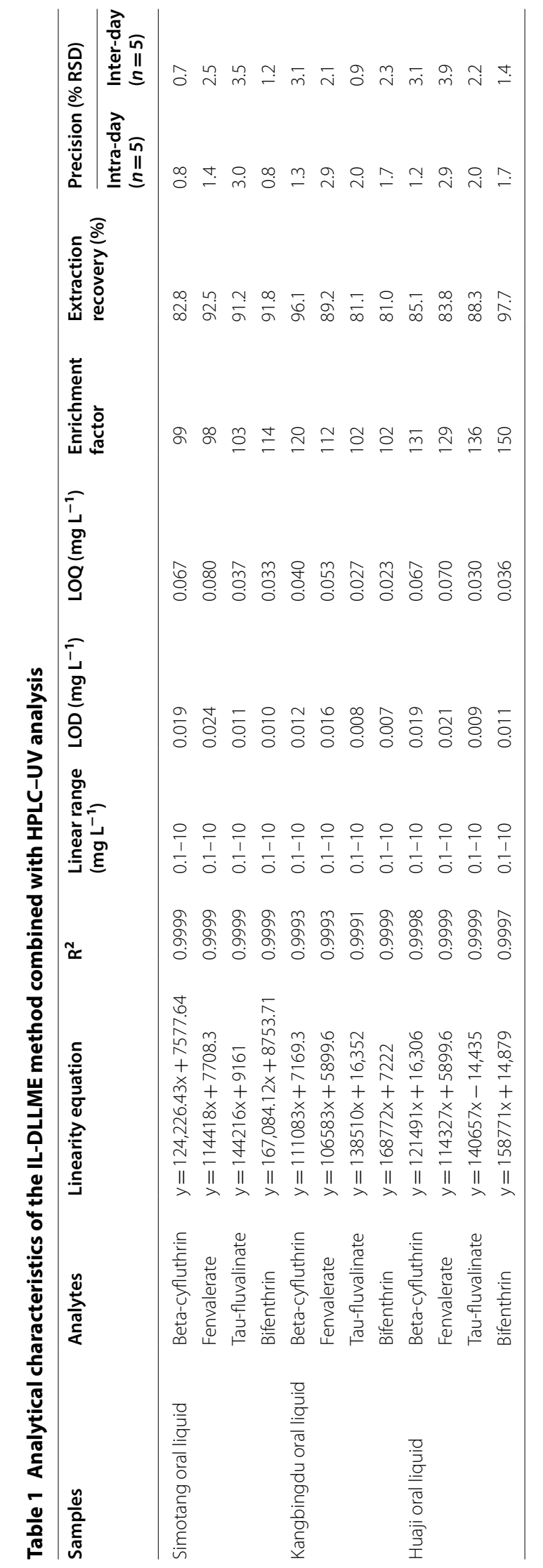


Table 2 Analysis of the TCM oral liquid preparations and spiked recoveries $(n=3)$

\begin{tabular}{|c|c|c|c|c|c|}
\hline \multirow[t]{2}{*}{ Samples } & \multirow{2}{*}{$\begin{array}{l}\text { Spiked } \\
\text { level }(\mu \mathrm{g} \\
\left.\mathrm{L}^{-1}\right)\end{array}$} & \multicolumn{4}{|c|}{ Relative recovery $\pm \mathrm{RSD}(\%)$} \\
\hline & & $\begin{array}{l}\text { Beta- } \\
\text { cyfluthrin }\end{array}$ & Fenvalerate & $\begin{array}{l}\text { Tau- } \\
\text { fluvalinate }\end{array}$ & Bifenthrin \\
\hline \multirow{3}{*}{$\begin{array}{l}\text { Simotang } \\
\text { oral } \\
\text { liquid }\end{array}$} & 20 & $95.7 \pm 1.3$ & $86.8 \pm 2.8$ & $100.6 \pm 2.9$ & $103.0 \pm 1.2$ \\
\hline & 50 & $83.7 \pm 2.6$ & $84.8 \pm 2.5$ & $89.7 \pm 2.9$ & $98.6 \pm 2.6$ \\
\hline & 100 & $92.7 \pm 2.1$ & $90.8 \pm 2.5$ & $94.6 \pm 1.6$ & $106.0 \pm 0.8$ \\
\hline \multirow{3}{*}{$\begin{array}{l}\text { Kang- } \\
\text { bingdu } \\
\text { oral } \\
\text { liquid }\end{array}$} & 20 & $94.7 \pm 0.9$ & $82.8 \pm 2.9$ & $91.0 \pm 2.6$ & $91.2 \pm 2.1$ \\
\hline & 50 & $96.1 \pm 2.1$ & $89.2 \pm 2.7$ & $81.1 \pm 1.4$ & $81.0 \pm 2.2$ \\
\hline & 100 & $97.2 \pm 2.4$ & $89.5 \pm 2.4$ & $90.2 \pm 2.7$ & $106.4 \pm 1.1$ \\
\hline \multirow{3}{*}{$\begin{array}{l}\text { Huaji oral } \\
\text { liquid }\end{array}$} & 20 & $81.9 \pm 3.0$ & $81.5 \pm 1.1$ & $81.5 \pm 1.3$ & $94.7 \pm 2.2$ \\
\hline & 50 & $85.1 \pm 3.1$ & $83.8 \pm 3.6$ & $88.3 \pm 2.2$ & $97.7 \pm 5.0$ \\
\hline & 100 & $84.4 \pm 2.1$ & $83.4 \pm 2.3$ & $80.1 \pm 1.3$ & $94.2 \pm 2.7$ \\
\hline
\end{tabular}

pretreatment approach is applicable for the measurement of pyrethroids in TCM oral liquid preparations.

\section{Comparison of the present approach with other approaches}

Table 3 lists a comparison of the current analytical approach with the published approaches for the measurement of pyrethroids in liquid samples [25-28]. Compared with other techniques, the current method consumed fewer types and lower amounts of organic solvents. In addition, although the sample matrix of a TCM oral liquid is very complex, the proposed method can provide LODs and enrichment factors comparable to other methods. Because this method has no special instrumentation requirements, it is highly applicable for the routine analysis of pyrethroids in TCM oral liquid preparations.

\section{Conclusions}

In the current work, a sensitive analytical approach was investigated for the measurement of four pyrethroids in TCM oral liquid preparations by the utilization of IL-UADLLME coupled with HPLC. The extraction parameters were investigated to improve the extraction efficiency, and excellent enrichment performance was achieved. The chromatographic conditions were also tested, and the chromatographic determination was achieved within 35 min. Compared with previous studies, although the sample matrix is more complex on account of the various of herbal component in TCM oral liquid, the proposed method achieved similar LODs with the utilization of less types and lower volume of toxic organic solvents during the microextraction procedure. The results reveal that the method is an accurate, simple, and environmentally
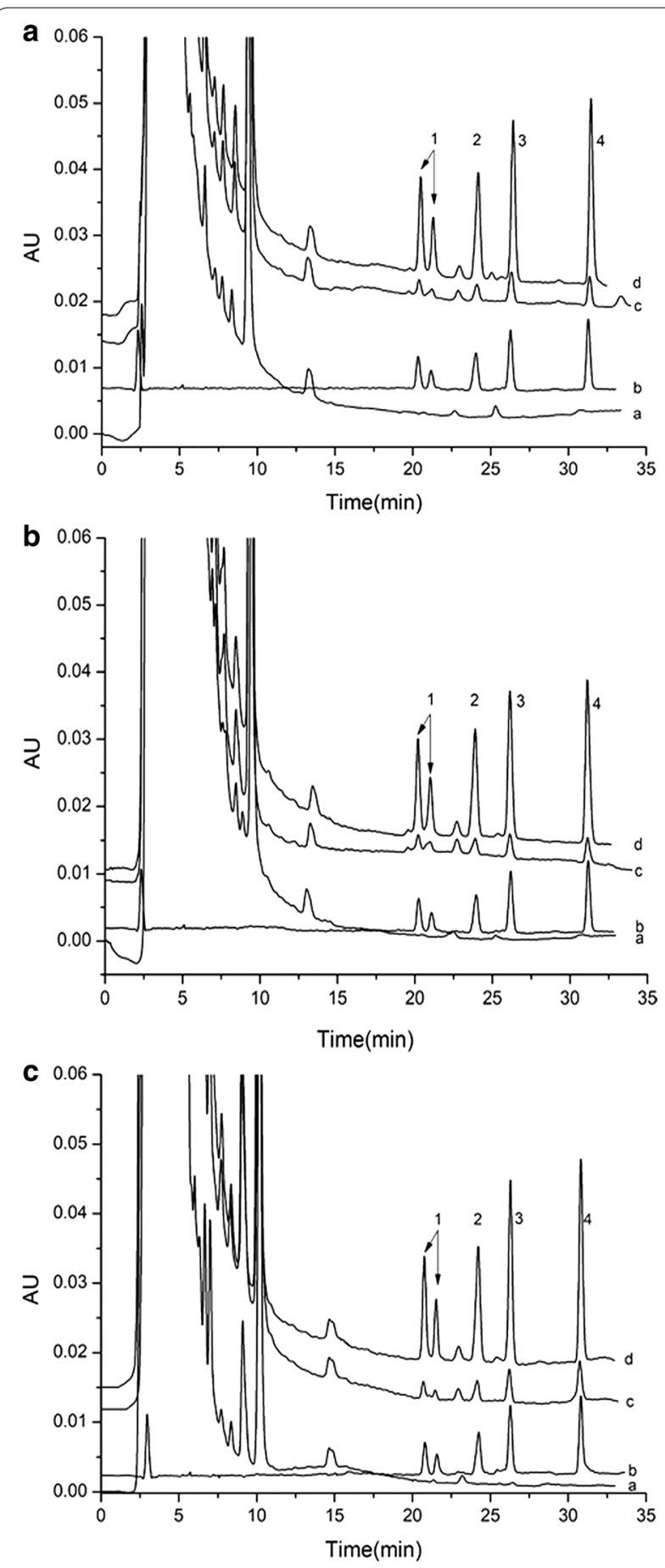

Fig. 3 Typical chromatograms of four pyrethroids in oral liquids-a simotang oral liquid, b kangbingdu oral liquid, c huaji oral liquidusing optimum conditions: (1) beta-cyfluthrin, (2) fenvalerate, (3) tau-fluvalinate, and (4) bifenthrin. In chromatograms (a, c, d), the spiked levels were $0,20,100 \mu \mathrm{g} \mathrm{L}{ }^{-1}$, and $\mathbf{b}$ shows the standard solution 


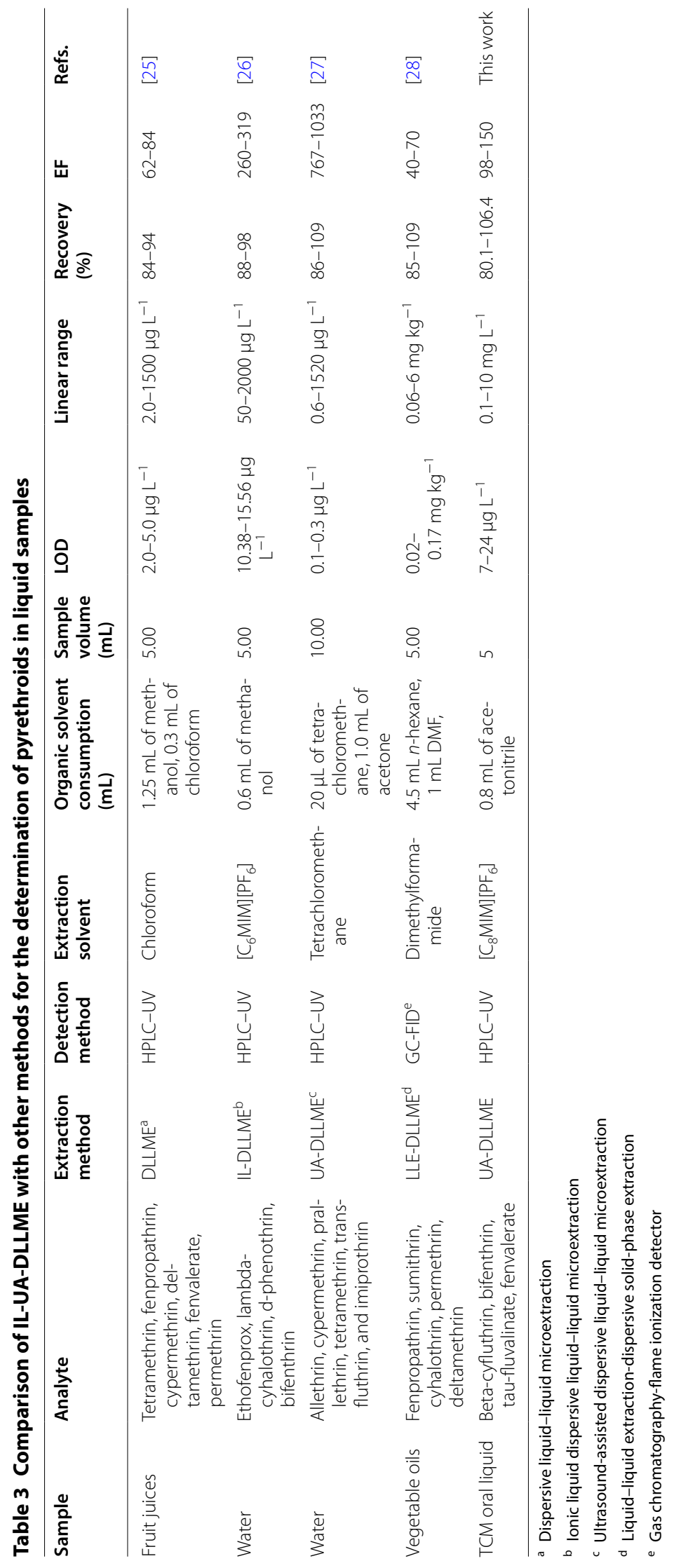




\section{friendly method for analyzing the pyrethroids in TCM oral liquid preparations.}

\begin{abstract}
Abbreviations
$\left[\mathrm{C}_{4} \mathrm{MIM}\right]\left[\mathrm{PF}_{6}\right]$ : 1-butyl-3-methylimidazolium hexafluorophosphate; $\left[\mathrm{C}_{6} \mathrm{MIM}\right]$ $\left[\mathrm{PF}_{6}\right]$ : 1-hexyl-3-methylimidazolium hexafluorophosphate; $\left[\mathrm{C}_{8} \mathrm{MIM}\left[\mathrm{PF}_{6}\right]\right.$ : 1-octyl-3-methylimidazolium hexafluorophosphate; EF: enrichment factor; ER: extraction recovery; IL-DLLME: ionic liquid dispersive liquid-liquid microextraction; ILs: ionic liquids; IL-UA-DLLME: ionic liquid-based ultrasound-assisted dispersive liquid-liquid microextraction; TCM: traditional Chinese medicine.
\end{abstract}

\section{Authors' contributions}

YS and YL designed research; $Y L, Y H, Y Z$, and $H C$ performed research; $Y L$ analyzed data; $Y S$ and $Y L$ wrote the manuscript; $C X, M T, Y Z$, and $S D$ revised the paper. All authors read and approved the final manuscript.

\section{Acknowledgements}

The research was supported by the Key Science and Technology Project of Hainan Province [ZDYF2018110], the National Natural Science Foundation of China [21505029], Grant from the Hainan Provincial Department of Education [Hnky2018-13] to YS and the Kobayashi International Scholarship Foundation to MT.

\section{Competing interests}

The authors declare that they have no competing interests.

\section{Availability of data and materials}

Please contact author for data requests.

\section{Funding}

This research was funded by the National Natural Science Foundation of China [21505029], the Key Science and Technology Project of Hainan Province [ZDYF2018110], Grant from the Hainan Provincial Department of Education [Hnky2018-13] to YS and the Kobayashi International Scholarship Foundation to MT.

\section{Author details}

1 Key Laboratory of Tropical Biological Resources of Ministry of Education; Department of Pharmaceutical Sciences, School of Life and Pharmaceutical Sciences, Hainan University, Haikou 570228, China. ${ }^{2}$ Graduate School of Pharmaceutical Sciences, University of Tokyo, Tokyo 113-0033, Japan.

Received: 7 August 2018 Accepted: 27 April 2019

Published online: 10 May 2019

\section{References}

1. Wang L, Chen Y, Song Y, Chen Y, Liu X (2008) GC-MS of volatile components of Schisandra chinensis obtained by supercritical fluid and conventional extraction. J Sep Sci 31(18):3238-3245

2. Wang L, Song Y, Cheng Y, Liu X (2008) Orthogonal array design for the optimization of supercritical fluid extraction of tanshinones from Danshen. J Sep Sci 31 (2):321-328

3. Wang Y, Zhang Y, Ji L, Hu Y, Zhang J, Zhang C, Ding G, Chen L, Kamijima M, Ueyama M, Gao Y, Tian Y (2017) Prenatal and postnatal exposure to organophosphate pesticides and childhood neurodevelopment in Shandong, China. Environ Int 108:119-126

4. Zhao HX, Zhao SC, Deng LG, Mao JS, Guo CY, Yang GS, Lu X (2013) Rapid determination of organonitrogen, organophosphorus and carbamate pesticides in tea by ultrahigh-performance liquid chromatography-tandem mass spectrometry (UPLC-MS/MS). Food Anal Method 6(2):497-505

5. Araki A, Miyashita C, Mitsui T, Goudarzi H, Mizutani F, Chisaki Y, Itoh S, Sasaki S, Cho K, Moriya K, Shinohara N, Nonomura K, Kishi R (2018) Prenatal organochlorine pesticide exposure and the disruption of steroids and reproductive hormones in cord blood: the Hokkaido study. Environ Int 110:1-13
6. Gil Garcia MD, Dahane S, Arrabal Campos FM, SociasViciana MM, Garcia MA, Femandez I, Martinez Galera M (2017) MCM-41 as novel solid phase sorbent for the pre-concentration of pesticides in environmental waters and determination by microflow liquid chromatography-quadrupole linear ion trap mass spectrometry. Microchem J 134:181-190

7. Tu W, Lu B, Niu L, Xu C, Lin C, Liu W (2014) Dynamics of uptake and elimination of pyrethroid insecticides in zebrafish (Danio rerio) eleutheroembryos. Ecotox Environ Safe 107(107):186-191

8. Singh A, Mudawal A, Shukla RK, Yadav S, Khanna VK, Sethumadhavan R, Parmar D (2015) Effect of gestational exposure of cypermethrin on postnatal development of brain cytochrome P450 2D1 and 3A1 and neurotransmitter receptors. Mol Neurobiol 52(1):741-756

9. Liu D, Min S (2012) Rapid analysis of organochlorine and pyrethroid pesticides in tea samples by directly suspended droplet microextraction using a gas chromatography-electron capture detector. J Chromatogr A 1235(8):166-173

10. Han Y, Song L, Liu S, Zou N, Li Y, Qin Y, Li X, Pan C (2018) Simultaneous determination of 124 pesticide residues in Chinese liquor and liquormaking raw materials (sorghum and rice hull) by rapid multi-plug filtration cleanup and gas chromatography-tandem mass spectrometry. Food Chem 241:258-267

11. Ghobadi M, Yamini Y, Ebrahimpour B (2015) Extraction and determination of sulfonylurea herbicides in water and soil samples by using ultrasoundassisted surfactant-enhanced emulsification microextraction and analysis by high-performance liquid chromatography. Ecotox Environ 112:68-73

12. Bartosz W, Marcin W, Wojciech C (2014) Development of hollow fibersupported liquid phase microextraction and HPLC-DAD method for the determination of pyrethroid metabolites in human and rat urine. Biomed Chromatogr 28(5):708-716

13. Capriotti AL, Cavaliere C, La Barbera G, Montone CM, Piovesana S, Zenezini Chiozzi R, Lagana A (2018) Chromatographic column evaluation for the untargeted profiling of glucosinolates in cauliflower by means of ultra-high performance liquid chromatography coupled to high resolution mass spectrometry. Talanta 179:792-802

14. Bagheri H, Yamini Y, Safari M, Asiabi H, Karimi M, Heydari A (2016) Simultaneous determination of pyrethroids residues in fruit and vegetable samples via supercritical fluid extraction coupled with magnetic solid phase extraction followed by HPLC-UV. J Supercrit Fluid 107:571-580

15. Smith PA, Thompson MJ, Edwards JW (2002) Estimating occupational exposure to the pyrethroid termiticide bifenthrin by measuring metabolites in urine. J Chromatogr B 778(1-2):113-120

16. Zhang P, Yu Q, He Y, Zhu W, Zhou Z, He L (2017) Chiral pyrethroid insecticide fenpropathrin and its metabolite: enantiomeric separation and pharmacokinetic degradation in soils by reversephase high-performance liquid chromatography. Anal Methods 9(30):4439-4446

17. Galera MM, Jlm V, Frenich AG, Mdg G (1996) Determination of cypermethrin, fenvalerate and permethrin in soil and groundwater by highperformance liquid chromatography using partial lest-squares regression. J Chromatogr A 727(1):39-46

18. Wang $K$, Xie X, Zhang Y, Huang Y (2018) Combination of microwaveassisted extraction and ultrasonic-assisted dispersive liquid-liquid microextraction for separation and enrichment of pyrethroids residues in Litchi fruit prior to HPLC determination. Food Chem 240:1233-1242

19. Mekebri A, Crane DB, Blondina GJ, Oros DR, Rocca JL (2008) Extraction and analysis methods for the determination of pyrethroid insecticides in surface water, sediments and biological tissues at environmentally relevant concentrations. B Environ Contam Tox. 80(5):455-460

20. Colume A, Cardenas S, Gallego M, Valcarcel M (2001) A solid phase extraction method for the screening and determination of pyrethroid metabolites and organochlorine pesticides in human urine. Rapid Commun Mass Sp. 15(21):2007-2013

21. Wang H, Hu L, Li W, Yang X, Lu R, Zhang S, Zhou W, Gao H, Li J (2017) Insyringe dispersive liquid-liquid microextraction based on the solidification of ionic liquids for the determination of benzoylurea insecticides in water and tea beverage samples. Talanta 162:625-633

22. Vichapong J, Burakham R, Srijaranai S (2016) Ionic liquid-based vortexassisted liquid-liquid microextraction for simultaneous determination of neonicotinoid insecticides in fruit juice samples. Food Anal Method. 9(2):419-426

23. Wang L, Zhang D, Xu X, Zhang L (2016) Application of ionic liquid-based dispersive liquid phase microextraction for highly sensitive simultaneous 
determination of three endocrine disrupting compounds in food packaging. Food Chem 197(Pt A):754-760

24. Zhang Y, Zhang Y, Zhao Q, Chen W, Jiao B (2016) Vortex-assisted ionic liquid dispersive liquid-liquid microextraction coupled with highperformance liquid chromatography for the determination of triazole fungicides in fruit juices. Food Anal Method 9(3):596-604

25. Boonchiangma S, Ngeontae W, Srijaranai S (2012) Determination of six pyrethroid insecticides in fruit juice samples using dispersive liquid-liquid microextraction combined with high performance liquid chromatography. Talanta 88(88):209-215

26. Wu T, Liu Y, Yang Z, Gao H, Zhou Z (2012) Determination of pyrethroid pesticides in environmental samples using ionic liquid dispersive liquidliquid microextraction. J Brazil Chem Soc 23(7):1327-1333
27. Yan H, Liu B, Du J, Yang G, Row KH (2010) Ultrasound-assisted dispersive liquid-liquid microextraction for the determination of six pyrethroids in river water. J Chromatogr A 1217(1):5152-5157

28. Farajzadeh MA, Khoshmaram L, Nabil AAA (2014) Determination of pyrethroid pesticides residues in vegetable oils using liquid-liquid extraction and dispersive liquid-liquid microextraction followed by gas chromatography-flame ionization detection. J Food Compos Anal 34(2):128-135

\section{Publisher's Note}

Springer Nature remains neutral with regard to jurisdictional claims in published maps and institutional affiliations.
Ready to submit your research? Choose BMC and benefit from:

- fast, convenient online submission

- thorough peer review by experienced researchers in your field

- rapid publication on acceptance

- support for research data, including large and complex data types

- gold Open Access which fosters wider collaboration and increased citations

- maximum visibility for your research: over 100M website views per year

At BMC, research is always in progress.

Learn more biomedcentral.com/submissions 